\title{
THE HYPOPHYSIS OF THE GUINEA PIG
}

\author{
C. M. VANDERBURGH
}

From the Department of Anatomy of Stanford University

SEVEN HIGURES

The guinea pig was used as the object of this study because it is readily obtainable and also because though thousands are used yearly for experimental purposes, this animal has been neglected from an anatomical standpoint. The only reference found to the anatomy of the hypophysis of the guinea pig, was one by Oppel ('14) who referred in a few lines to its general relations and another by Paulesco ('08) who quotes Fischera in regard to the weight of the gland.

The general relations of the hypophysis of the guinea pig are very similar to those existing in other vertebrates and its microscopic structure is quite similar. The most striking difference found was the presence of cilia in the cleft and also in the epithelial cysts or vesicles of the glandular portion. According to Trautman ('09), ciliated epithelium has been reported in the vesicles in the hypophysis of man and the rabbit, but Trautman was unable to find any in the cysts of any of the domestic animals studied by him. These included the horse, ass, cow, calf, sheep, goat, hog, dog and cat, and although he could not be certain Trautman thought he saw ciliated epithelium in the lining of some portions of the cleft of the pituitary of the hog. In the guinea pig this ciliated epithelial lining of both the cleft and the vesicles was found uniformly present somewhere in all the specimens examined, but it was not present in all cysts nor did it completely line the clefts. Within the latter, in fact, it did not appear at all on the side adjacent to the pars intermedia and only on portions of the opposite side. These portions are easily recognizable even under low magni- 
fication by the large, clear, columnar cells, which often project into the lumen, as little mounds. In some cases, however, the ciliated portion of the lining epithelium extends over considerable stretches. The fact that ciliated epithelium is present in both the cleft and in the closed vesicles of the epithelial portion seems to indicate that their origin is the same and that both undoubtedly are remnants of the lumen of the epithelial pouch (Rathke's pouch) developed from the buccal epithelium. In several cases, for example, it was possible to trace the lumen of typical vesicals to the lumen of the cleft.

\section{METHODS}

In every case a portion of the brain was removed with the hypophysis in order to retain its relations, particularly with the third ventricle. All microscopic preparations were cut serially in paraffine. Sections cut sagitally in the cranio-caudal plane were used mostly since they best show the relations of the different parts. Zenker's fixative, followed by methylene blue and aqueous eosin were found to be the best general fixative and stain. Flemming's and Orth's fluids were also used. The phosphotungstic acid-hematoxylin stain was found valuable in staining neuroglia and ependymal fibers and cells, and also reticular connective tissue. Next to the methylene blue and eosin, aqueous eosin and iron-hematoxylin were found to be most satisfactory. The latter stains the cell boundaries especially well (figs. 3 and 4 ).

\section{OBSERVATIONS}

The hypophysis of the guinea pig is comparatively large. Measurements made upon three freshly killed adult animals show that it weighs between 22 and $32 \mathrm{mgm}$., varying somewhat in different specimens. Paulesco ('08) quotes Fischera as giving the weight of the gland as 0.015 gram, but he does not state whether his data were derived from specimens of fresh or preserved glands. By weighing the brain also in each case, 
it was calculated that the gland represents between 0.52 per cent and 0.70 per cent of the total brain weight.

The measurements made on formaline fixed glands as to size gave the following averages:

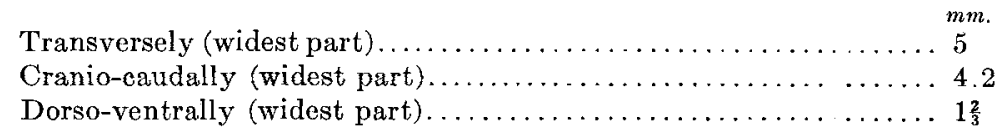

The brain proper, including the cerebellum had the following average dimensions:

Tran.

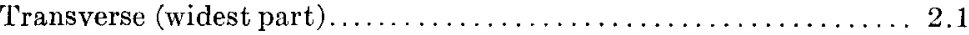

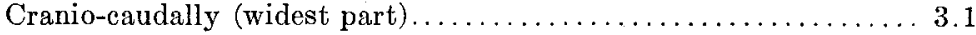

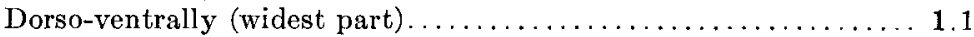

From the above measurements it will be seen that the hypophysis is comparatively large; that its transverse diameter is about one and a fourth the cranio-caudal diameter and that it is much flattened dorso-ventrally.

The general relations of the gland to the brain are indicated in figure 1, which is a semi-diagrammatic sketch of the inferior surface of the brain with the dura mater removed. The hypophysis lies just posterior to the optic chiasma in an almost horizontal plane, being practically parallel to the plane of the base of the brain. The cerebrum, descending on either side, forms a considerable fossa in which lies the pituitary with its dural sheath, the blood vessels and sinuses. Laterally on either side and partly covering it, lie the two very large fifth nerves with their ganglia. The gland is attached to the tuber cinereum by a comparatively long stalk which expands posteriorly forming the pars nervosa. In the figure only a small portion of the pars nervosa is visible posteriorly, from the inferior surface, for the greater part of it is covered by the pars glandularis. The dorsal end of the gland is free except where it is attached to the brain by the blood vessels which enter its superior surface.

The dura mater forms a distinct pouch or pocket for the whole gland and is much thickened behind where it is often cartilaginous in old animals. In section it shows that it is split off from the main dural covering of the brain, but the cavity of the 
pocket is nevertheless continuous with the main subdural space. The gland is loosely attached to the dura by little strands of arachnoid tissue but the space between is easily penetrated by fluids.

A large vascular sinus surrounds the posterior end of the gland in a horizontal direction between the two layers of the dura mater which is here split to form the dural pocket. Its walls are thin and composed only of a thin layer of fibrous

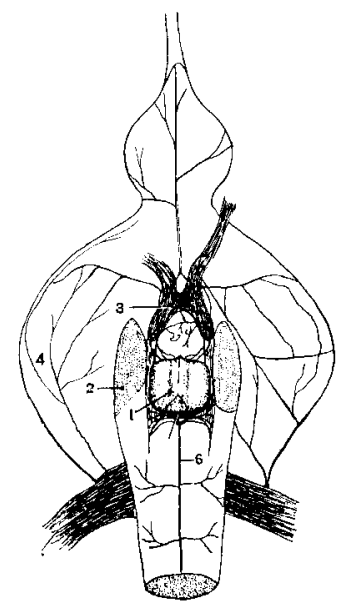

Fig. 1 Diagrammatic sketch of the inferior surface of the brain of the guinea pig showing position of the pituitary gland and its relation to the surrounding structures. 1, pituitary; 2 , divided fifth nerve and semilunar ganglion; 3 , optic chiasma; 4 , cerebrum; 5 , small portion of pars nervosa projecting from above the pars anterior; 6 , basilar artery.

tissue lined by endothelium. The lumen fits the space between the two dural layers and therefore bas a general triangular shape but it is often irregular. Sometimes it partially replaces the subdural space extending anteriorly over the superior or inferior surfaces or over both for varying distances. In these cases the fibrous layer is inseparably fused with the capsular layer of the gland. In animals in which the arterial system was injected with India ink this sinus shows very distinctly as a black line extending around the posterior end of the gland. 
About the middle of the posterior end of the gland there is a smaller connecting sinus which extends directly posteriorly within the dura mater, presumably forming a connection with some other blood vessel. There is nothing to indicate the function of these venous vessels but it seems probable that they drain some portion of the pituitary, probably the meninges. The circular sinus of the pituitary was found in every series of sections observed but the sinus passing posteriorly could only be seen when the krife happened to pass parallel to its lumen. That they were sinuses and not lymph channels, was shown by the fact that they were often engorged with blood.

The hypophysis with its dural covering, lies upon the posterior third of the body of the sphenoid bone. The sella-turcica is represented only by a small fossa, at the bottom of which there is usually a small opening. If closure of the cranio-pharyngeal canal is partly or wholly prevented by the persistence of the epithelial stalk, this minute aperture, opening into the bone may thus remain. In no case, however, had the stalk retained its epithelial structure and in most cases no trace of it could be found. Within the sphenoid the canal is more or less obliterated by encroachment of the bone. On the pharyngeal or inferior surface a second foramen which transmitted the buccal end of the stalk is sometimes seen.

The relations of the different parts of the hypophysis can best be understood by referring to figure 2. The epithelial portion lies upon the inferior surface and is represented by the darkened area. In section it appears smaller than the light area or pars nervosa but, owing to the fact that it extends so far laterally, amost surrounding the nervous portion here and anteriorly actually doing so (9) it is really considerably-probably a thirdlarger than the pars norvosa. It extends as a thin epithelial layer anteriorly over the neck and also over the base of the tuber cinereum. For this reason this part is called the pars tuberalis (4) by Tilney '14. Tilney claims for it a separate development from Rathke's pouch.

The infundibulum cerebri (fig. 2) is a continuation of the brsin backwards and slightly downwards. It originally con- 
sisted of brain tissue but apparently degenerates laterally into a connective tissue mass containing a few epithelial cells. Colloid is found in the meshes but this probably has its source in the pars intermedia. The infundibulum which is funnel-shaped near the base of the brain becomes comparatively small at its neck and at the distal end widens out into a club-shaped mass, which forms the main portion of the pars nervosa. In some animals, notably the cat, the posterior lobe is hollow, but in the guinea pig it is nearly solid, the opening from the third ventricle ending in the neck as seen at 5 and 6 in the figure. The

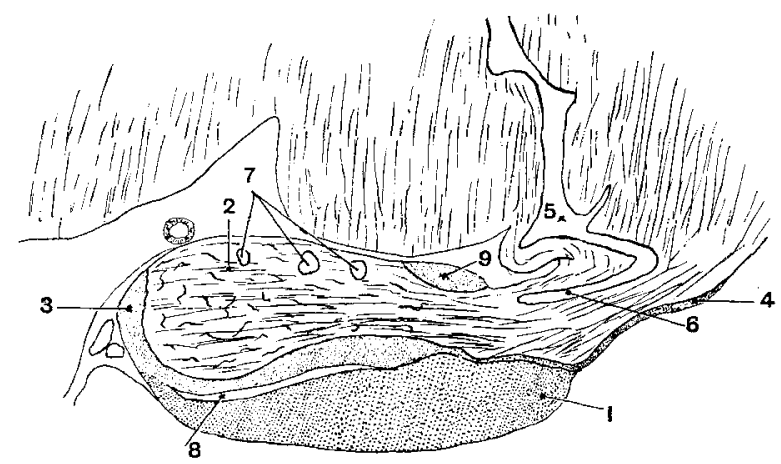

Fig. 2 Median sagittal section through pituitary of adult guinea pig. (Semidiagrammatic) 1, pars anterior; 2 , pars nervosa; 3 , pars intermedia; 4 , tonguelike process of pars tuberalis of intermediate lobe; 5 , third ventricle; 6 , recessus infundibuli; 8 , cleft; 9 , portion of intermediate lobe which completely surrounds the pars nervosa.

end of the cavity usually enlarges to form a small irregular bulb. In most cases the nervous lobe is not absolutely solid but contains cysts ( 7$)$ of varying size which are presumably remnants of the foetal condition in which the lumen of the third ventricle extended down into the body of this lobe.

The pars glandularis is differentiated into two portions, the pars anterior (1) and the pars intermedia (3). These parts are partially separated by a cleft $(8)$ which is described as the remains of the lumen of Rathke's pouch by Tilney '14, Herring '08 and also. byy others. 
THE PARS ANTERIOR

The pars anterior is composed of columns of epithelial cells with blood sinuses separating them (fig. 3). Presumably, the secretion from the cells is absorbed directly into the circulating blood. The cells of the pars glandularis are large and glandular and have different staining characteristics. Usually there is a distinct investment of basophilic cells upon the peripheral surface, the interior being composed mostly of acidophile
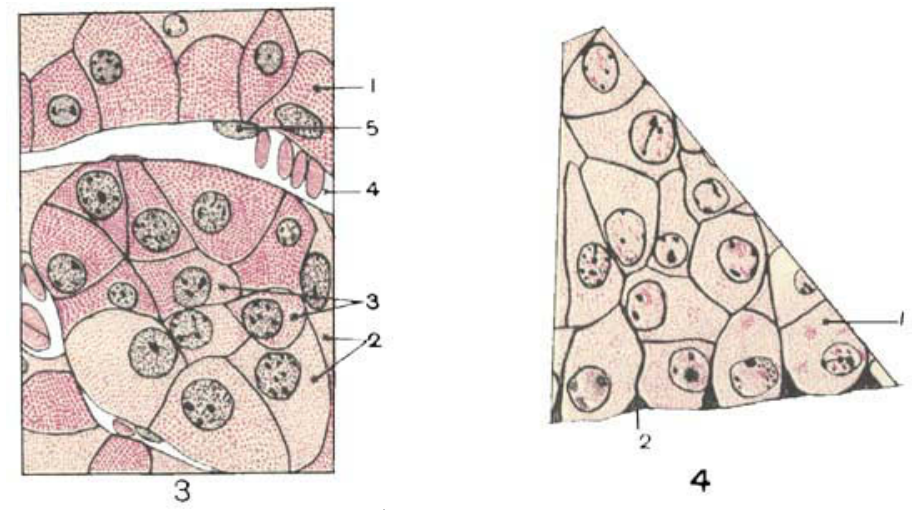

Fig. 3 Drawing made from section of pars anterior of guinea pig's pituitary. Stained deeply with iron hematoxylin and aqueous eosin. 1, decply staining acidophile cells with large granules; 2 , nearly clear cells slight, 1 stained (neutrophiles); 3 , intermediate stages; 4 , blood sinus containing blood corpuscles; 5 , large nucleus of cell lining blood sinus.

Fig. 4 Section of pars intermedia of pituitary of adult guinea pig stained with iron hematoxylin and aqueous eosin. 1, typical cell with fine granules; 2, branched supporting cells. The base of the drawing is the part adjacent to the cleft.

cells. The nuclei are large and distinct and show many variations in regard to the chromatin. A peculiarity of this portion of the gland is the marked richness of the blood supply. In this respect it differs remarkably from the pars intermedia in which the blood supply is very scanty indeed.

There has been much discussion of the significance of the different staining characteristics of the cells of the anterior lobe but it is not necessary to give a historical account of the 
different opinions here. Herring '08 considers the subject in some detail. It suffices to say that some authors describe three and four different kinds of cells according to differences in staining and ascribe different functions to each. Others claim that the different staining characteristics are due to differences in secretory activity of the cells. My observations upon the guinea pig tend to confirm the latter view. The different staining characteristics are, of course, always present to a very striking degree. With methylene blue and eosin, some cells are notably acidophilic, others notably basophilic. But between these two extremes all gradations in staining were found (fig. 3). Nor could any uniform difference in the shape and size of the differently staining cells be seen. The structure of the nuclei is apparently the same and they are subject to the same irregularities in size in the different types of cells.

In addition to the cells which constitute the anterior lobe proper which were described above, there are reticular cells which can be recognized by their opaque and uniform stain and also the cells lining the bloodvessels.

The pars anterior is nowbere in contact with the pars nervosa for a portion of the pars intermedia always intervenes. No colloid is found between the cells of the pars anterior but the vesicles especially characteristic of the pars intermedia were also occasionally found.

The portion of the anterior lobe which lines the cleft is composed of a single layer of epithelial cells. These ceils are sometimes irregular, cuboidal or columnar. The columnar cells are usually ciliated. They are most regularly found at the posterior end of the cleft but may appear in little mounds anywhere along the cleft on the side adjacent to the anterior lobe (fig. 6). Beneath this layer of epithelium there are usually found true capillaries and spaces which may or may not be lymph spaces as suggested by Herring. In this portion connective tissue cells are most abundant. 
The pars intermedia or juxta-neural portion is described as arising from the same source as the pars anterior, namely from Rathke's pouch. In a guinea pig at birth there is little differentiation between these portions but in the adult the difference is striking. There are no intensely acidophilic cells in the pars intermedia (fig. 4). At the point of junction at either end of the cleft, the change from the intensely red cells in cases of eosin staining, usually found in that region to the smaller lightly staining cells of the pars intermedia is quite abrupt. Herring ('08) found that this is not always the case in the cat, but in the guinea pig the abruptness of the transition was quite striking in every series of sections examined.

The pars intermedia partly invests the pars nervosa. The whole of the inferior and lateral surfaces and the greater part of the superior surface of the latter is covered by a comparatively thick layer of epithelial cells. However, posteriorly and superiorly there always is a region in which there is no epithelial investment. Here many of the bloodvessels of the parsnervosa enter, and just within the nervous substance, lie the remnants of the lumen developmentally continuous with the third ventricle, which are shown in figure 2 . It may be significant that these remnants, or residua of the lumen, are always found in that region. They often get so near the surface that only the general connective tissue covering of the gland lies between them and the subdural space. In no case, however, could an opening from one into the other be found.

The cells of the intermediate are slightly smaller than those of the anterior lobe. Their nuclei are perbaps a little smaller but they have the same general appearance and stain uniformly. They are slightly acidophile but with an excess of basic stain will stain basic. Sometimes they are finely granular but they never contain the coarse granules of the acidophilic cells of the anterior lobe. Connective tissue cells are quite abundant especially along the cleft, where the branched supporting cells are much in evidence (fig. 4). According to Retzius who 
is quoted by Herring, these cells in the cat "are for the most part small and thread-like and reach through the whole border. Others do not pass through but are branched. The cell nuclei are often placed near the outer end, while the inner end widens to a three-cornered foot, which is placed against the nervous tissue of the posterior lobe." With the stains used, it was impossible to confirm these statements satisfactorily in the guinea pig, but supporting cells extending from the cleft towards the pars nervosa were seen. They were branched and unbranched. and their enlarged nuclei usually were situated between the extreme ends of the cells lining the cleft or just within their outer border. In the former case they appear as little black triangles (fig. 4) which were moulded to fit the inter-space between the cells while, in the latter, they were much elongated and usually more transparent.

A very striking difference between the pars anterior and pars intermedia is the great wealth of blood supply in the one and its almost total absence in the otber. A few capillaries only were found in the posterior portion of the pars intermedia but in the anterior portion, especially where it caps the pars anterior in the region of the neck, a great many were found which pass into the large arteries and veins of the neck of the infundibulum. In this case, however, the capillaries are comparatively large and apparently furnish only a small supply of blood to the surrounding tissues. However, at the junction of the pars intermedia and the pars nervosa there is usually an abundant vascular supply. In sections a vessel containing erythrocytes can nearly always be identified between these two portions of the hypophysis.

\section{THE CLEFT}

The cleft which partially separates the pars anterior from the pars intermedia, is a persistent portion of the lumen of Rathke's pouch. Upon the further separation of the infundibulum from the pharynx by the growth of the intervening parts, the infolding pouch is described as being drawn out into a long tube connecting the bulbous expansion of the cranial end with 
the pharynx. The tube ultimately disappears, but the bulbous expansion partially remains and is represented in the adult by the cleft of the pituitary. It is always present in the guinea pig but it is not nearly so extensive comparatively as in the cat. Posteriorly and laterally it is often branched and irregular. In these localities cysts are most often found, especially at the posterior and anterior ends of the cleft. These evidently are portions cut off from the main cleft, which retain the original lumen as the lining of the cysts. The cleft is lined superiorly and posteriorly by the epithelium of the intermediate lobe; inferiorly and anteriorly by the cells of the anterior lobe. These lining cells are sometimes high columnar and ciliated and are usually only one cell deep.

The 'colloid' vesicles or epithelial cysts or acini,-—various names are used synonymously by different authors - are especially characteristic of the pars intermedia. These cysts are of varying size, being usually largest and most numerous at either end of the cleft and, as pointed out above, are without doubt, merely portions of the original epithelial pouch, which have been cut off from the original lumen in the process of its partial obliteration. The cysts are surrounded by a single layer of epithelium. In some cases this is cuboidal but in others it is high columnar and ciliated. Some cysts contain both kinds of cells. One end of a cyst may have low cuboidal cells which further on, may gradually assume the typical high columnar form. The fact that portions of the epithelial lining of these cysts are usually ciliated and that the same type of ciliated cell is also found lining the cleft, alone strongly suggests a common origin. But what is more convincing is that in a few cases it was found possible to trace the lumen of the cyst to the cleft. Figure 5 is a drawing, outlined by the aid of a camera lucida of such a typical epithelial vesicle, the cavity of which could be traced to a direct connection with the cleft. The cell boundaries were not well-defined owing to the fact that the section was stained with methylene blue and eosin, which, though giving a high transparency and clearness does not stain the cell boundaries well. The cilia were quite clear and dis- 

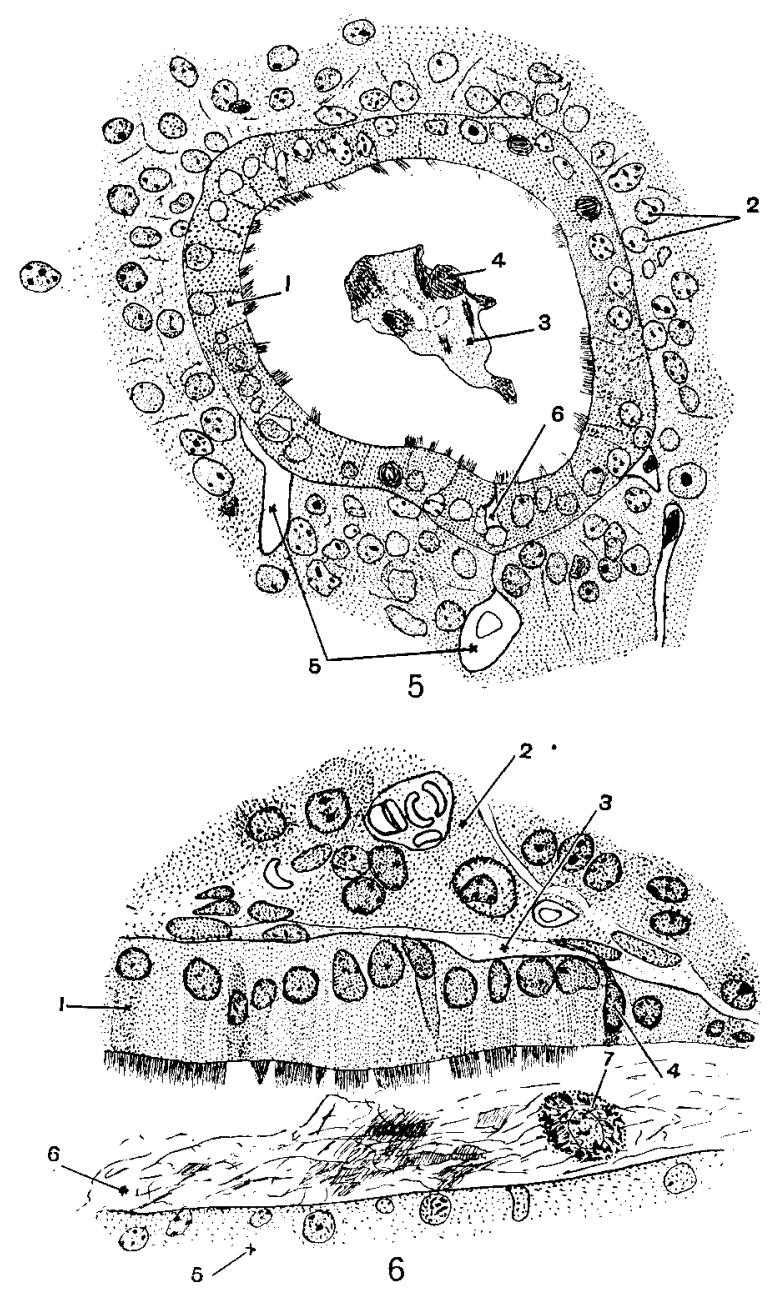

Fig. 5 Drawing of a cyst from the pars intermedia. 1, ciliated columnar cells surrounded by nuclei (2) representing cells of pars intermedia. The cell boundaries did not stain; 3, granular contents containing (4) a degenerating cell; 5 , blood vessels of pars intermedia; 6 , blood vessels entering between cells of vesicle.

Fig. 6 Portion of cleft lined by ciliated epithelium. Stained with methylene blue and eosin. 1, ciliated columnar epithelium; 2, cells of pars anterior; 3, blood vessel usually present above the row of lining epithelium; 4, supporting cells. Note absence of eilia at this point; 5 , location of pars intermedia; 6 , granular fibrinous mass suggesting coagulum containing (7) a very large degenerating epithelial cell, the nucleus of which still contains characteristic granules. 
tinct and normal looking in this specimen. In some cysts they are formed into little tufts, one for each cell, while in others they seemed to project quite uniformly from the whole circumference of the lining epithelium. In other cases they were pulled away by the contraction of the contents of the cysts during fixation.

These vesicles were rarely found in the pars nervosa also, but in no case was there ciliated epithelium lining them. In two specimens typical ciliated cysts were found lying practically wholly outside the gland in the region of the original attachment of the epithelial pouch at the extreme anterior end of the glandular portion in both cases. They were probably persistent portions of the stalk. In one of the two cases the cyst could be traced as far as the dura where it merged with the connective tissue, the bounding cells showing marked signs of disintegration.

Many authors have described colloid as existing in these cysts and also in the cleft, but none could be found in either place in the guinea pig. Its absence did not seem to be due to defective fixation or staining, for the colloid found elsewhere in the pars intermedia and particularly in the neck of the infundibulum was both well-fixed and well-stained. Most of the vesicles contained a granular mass without any particular structure evidently derived from degenerated epithelial cells, for cell detritus was often found in the mass and cells apparently being detached from the walls of the cyst were also seen. This cell detachment did not seem to be an artefact for it was found many times in areas where the other cells showed no signs of damage and were fixed perfectly. The degenerating cells, in some cases, were drawn out into a pear shape, the small end of the pear alone being still attached.

The degenerating cells in the cleft seemed to come from the pars glandularis. Some of these cells still retained their acidophile properties but did not show clear-cut granules. They contained a substance resembling mucous in appearance and staining qualities, and wholly unlike the colloid found in the posterior lobe. 
There has been very much discussion of the structure and function of the pars nervosa. Some writers, notably Berkley ('94) have described nerve cells. Berkley described several different kinds of cells but the work of later investigators seems to disprove the presence of any nerve cells whatever and it seems that the earlier authors probably mistook the ependymal and connective tissue cells. The posterior lobe seems to be made up of a mass of interlacing ependymal and neuroglia cells and fibers running in a general longitudinal direction. Occa-

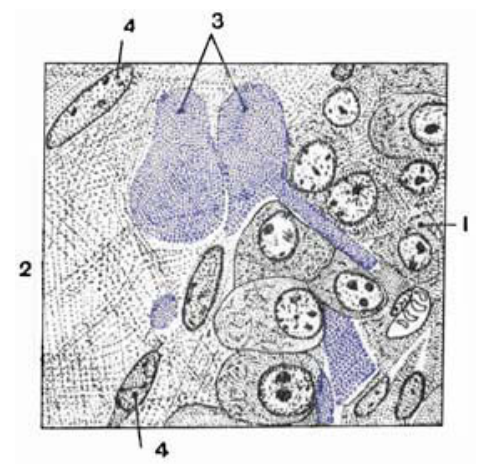

Fig. 7 Section through part of pars intermedia and pars nervosa at their point of junction. 1, cells of pars intermedia; 2 , pars nervosa; 3 , colloid appearing both in pars nervosa and pars intermedia. Note the granular appearance of the colloid; 4, neurolgia nuclei.

sionally there are little clumps of what may be epithelial cells, though, in the guinea pig, they are small and not characteristic. For information on the pars nervosa reference is made to Herring. Herring worked upon the cat which is an animal more satisfactory for this study than the guinea pig because the pars nervosa of the cat is hollow and its lumen directly continuous with the third ventricle.

In the guinea pig there are few inclusions of epithelial cells in the pars nervosa. Figure 7 shows a portion where the epithelial cells had pushed their way slightly into the substance of the nervous portion. It was the only place in the section. 
Here, as indicated, the colloid material of the pars nervosa and that of the pars intermedia are directly continuous. In fact, one mass of colloid lies partly in both portions. It has the appearance of having been fixed while passing from the one into the other. There were few cells in the pars nervosa that could possibly be secretory. Hence it seems reasonable to suppose that the colloid secretion was passing from the pars intermedia into the pars nervosa. Physiological experiments also support this view. Moreover where the tongue-like process of the pars intermedia extends over the base of the tubercinereum which is not connected with the pars nervosa of the pituitary, the colloid is often found in the substance of the latter structure. In this region there are no closed vesicles as in the pars nervosa and little evidence of any epithelial inclusions. This would also seem to exclude the theory that in the guinea pig the colloid results from the degeneration of epithelial cells in the pars nervosa, and also the possibility of the secretion being produced in the pars nervosa. Colloid is often found in greatest abundance in the neck of the infundibulum. The structure of the nervous portion does not seem to account for its importance and since the epithelial cells of the middle lobe have been in contact with it from an early stage of development it would seem that its importance lies in this relationship. That is, that the secretion from the intermediate lobe passes through the pars nervosa into the brain substance perhaps on its way to absorption by the cerebrospinal fluid.

In the guinea pig the ependymal cells of the different parts of the nervous portion seem to vary. In the neck and therefore near the end of the recessus infundibuli they are quite distinct and can be traced for some distance gradually merging into ependymal fibers. In the body of the lobe, they seem to lose much in staining properties and therefore in distinctness. There are, indeed, many fibers running in bundles in all directions but they are smaller and are indistinct while the cells themselves can hardly be recognized although their large nuclei are always very striking. 
The cysts found in the pars nervosa of the guinea pig presumably are the remains of the original cavity of the recesses infundibuli. They are lined with a thin layer of connective tissue, which gives no clue to its origin. In different animals, there is a variation in their size. In one specimen the opening was quite large and could be traced very nearly to the end to the retained recess in the neck. These cysts are usually filled with a granular mass somewhat similar to that found in the colloidal cysts of the pars intermedia. A lining membrane is not always present.

In every series of those sections in which the dural pocket was retained with the gland the so-called parahypophyses were found. Their most usual situation was in that portion of the dura which covers the inferior surface of the neck or infundibulum of the gland, but they were found anywhere in the dural covering of that structure. They are glandular in structure but are much degenerated and probably nonfunctioning.

In one series of sections a vesicle of the pars intermedia situated near the neck of the gland, was traced across the subdural space into the dura and in later sections appeared as a characteristic parahypophysis. Since these vesicles are probably unobliterated portions of the lumen af Rathke's pouch, it follows that these pseudoglands are merely remnants of the walls of the pouch for the two are continuous.

In two of the above series of sections, a peculiar cartilaginous structure was found, situated between the dura mater and the sphenoid bone. It had practically the same appearance in both cases in which it was found. It consisted of a comparatively long partly tubular cartilaginous structure, extending from the anterior portion of the gland to beyond the posterior end by about one third the length of the gland. That side of the cartilaginous tube adjacent to the sphenoid bone was partly missing and the remaining portion showed defects in staining and possessed no perichondrium. There was no evidence of any tearing for the edges were smoothly rounded off where the defect in the tube commenced. The cartilage next the dura was about ws thick as that structure and was apparently normal. The 
perichondrium was in places fused with the dura. The lumen of the cartilaginous 'tube' was lined by columnar ciliated epithelium. In some places this lining was much degenerated, but at others and particularly at either end, the epithelium was quite characteristic of the epithelial lining of the mucous membrane. Moreover, there were numerous mucous glands whose lumen could be traced directly into that of the tube, leaving no doubt as to the origin of epithelial lining from mucous membrane. I saw no evidence regarding the probable origin of the cartilage, however. In one of the two series referred to above, the anterior end of the tube could be traced through the sphenoid bone to the pharynx where it apparently stopped.

\section{SUMMARY}

1. Ciliated epithelium was found to line some portions of the side of the cleft adjacent to the pars anterior but was never found on the opposite side.

2. The so-called 'colloid vesicles' of the cysts of the pars intermedia and occasionally of the pars glandularis are usually lined with ciliated epithe ium.

3. From the above two considerations and also from the fact that in the adult guinea pig, the lumen of an apparent cyst can sometimes be found continuous with the lumen of the cleft, the conclusion that these cysts and the cleft have the same origin is justified.

4. No colloid-like substance was found either in the cleft or in the vesicles. Both contained granular substances embedded in what stained and appeared like mucous, and which occasionally contained degenerated epithelial cells. These cells seemed to have broken off from definite regions of the lining.

5 . The only substance resembling the colloid of the thyroid gland was found in the pars intermedia and nervosa, especially in the neck of the latter. Also, very often it was found in that portion of the tubercinereum covered by epithelium. This substance occasionally has a granular and hyaline appearance, thus differing from the colloid of the thyroid. 
6. Apparently the colloid just described is a secretion of the pars intermedia passing via the pars nervosa into the brain substance, perhaps to be absorbed into the cerebro-spinal fluid.

In concluding I wish to express my thanks to Professor Meyer for his assistance, helpful suggestions and criticisms in the preparation of this paper.

\section{IITERATURE (ITHD}

BERKLLFY 1894 The finer anatomy of the infundibular region of the ce:ebrum including the pituitary gland. Brain, volume 17.

Cushing, H. and Gomtsch, E. 1910 Concerning the secretion of the infundibular lobe of the pituitary body and its presence in the cerebrospinal fluid. Philadelphia and London.

Dandy, W. E. AND Goerscr, E. 1911 The blood supply of the pituitary. Am. Jour. Anat., vol. 2.

Edinger, L. 1911 Die Ausführwege der Hypophyse. Archiv für mikroscopische Anatomie, Band 78.

Herring, P. L. 1908 The microscopical appearance of the mammalian pituitary body. Quar. Jour. Exper. Physiol., Jena.

1908 The development of the mammalian pituitary and its morphological significance. Quar. Jour. Physiol., vol. 1.

Oppes, Albert 1914 Lehrbuch der vergleichenden mikroskopischen Anatomic der Wirbeltierc, Achter Teil. Gustav Fischer, Jena.

Paulesco, C. 1908 I'Hypophyse de Cerveau. Paris.

Stendell, W. 1913 Zur vergleichenden Anatomie und Histologie der Hypophysis cerebri. Arch. f. mikr. Anat., Bd. 82.

Tilney, Frederick 1914 An analysis of the juxta-neural epithelial portion of the hypophysis cerebri with an embryological and histological account of a hitherto undescribed part of the organ. Internat. Monat. f. Anat. u. Physiol., Bd. 30.

Thatiman, Alfred 1909 Anatomie und Histologie der Hypophysis cerebri einiger Saüger. Arch. f. mikro. Anat., vol. 74 . 